\title{
Metal-Urea-Montmorillonite Hybrid Incorporated with Citric Acid
}

\author{
Kwang Seop Kim*, Min-Tae Kim, Jin-Hee Ryu, Jong-Seo Choi, Ki Do Park, Hang-Won Kang, and Man Park*** \\ Crop Environment Division, National Institute of Crop Science, RDA. Suwon 441-857, Korea. \\ ${ }^{1}$ Soil Science Lab. College of Agriculture and Life Science, Kyungpook National University, Daegu 702-701, Korea.
}

(Received: November 7 2013, Accepted: December 2 2013)

\begin{abstract}
Massive intercalation of urea into montmorillonite (MUCH) was recently proposed to enhance urea use efficiency through smart suppression of emission of $\mathrm{NH}_{3}$ and NOx. This study was to synthesize citrate-incorporated MUCH (Cit-MUCH) which can enhance suppression of $\mathrm{NH}_{3}$ volatilization. The XRD pattem of Cit-MUCH was very similar to that of MUCH to indicate successful incorporation of citric acid into MUCH. Incorporation of citric acid was confirmed by the existence of $\mathrm{COO}^{-}$symmetric stretching vibration. During the initial 4 days after application, $\mathrm{NH}_{3}$ volatilization from both bare and perilla-planted soils was much more suppressed by application of Cit-MUCH than MUCH. A peak volatilization rate decreased from $28.3 \mathrm{~N} \mathrm{mg} \mathrm{m}^{-2} \mathrm{~h}^{-1}$ of MUCH-broadcasted soil to $22.2 \mathrm{~N} \mathrm{mg} \mathrm{m}^{-2} \mathrm{~h}^{-1}$ of Cit-MUCH-broadcast soil. $\mathrm{NH}_{3}$ volatilization was less in planted soil than bare soil for $72 \mathrm{hrs}$ after application. These results showed that incorporation of citric acid led to increase in suppression of ammonia volatilization from urea-applied soils.
\end{abstract}

Key words: Ammonia volatilization, Urea use efficiency, Citric acid, Massive intercalation, Montmorillonite

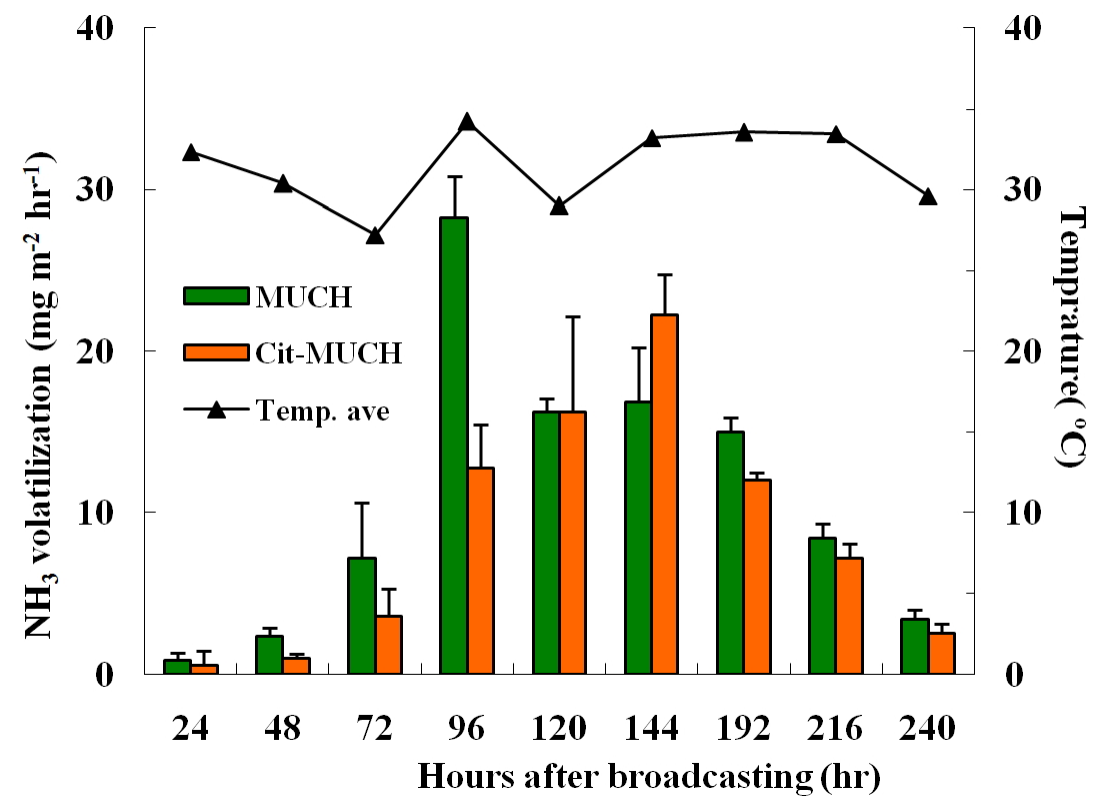

Effect of the citric acid incorporated $\mathrm{MUCH}$ on $\mathrm{NH}_{3}$ volatilization from a bare soil.

\footnotetext{
*Corresponding author : Phone: +82312906785, Fax: +82312906773, Email: can3838@korea.kr

**Co-corresponding author : Phone: +82539505717, E-mail: manpark@knu.ac.kr

${ }^{\S}$ Acknowledgement: This study was supported by Technology Development Program for Agriculture and Forestry (No. 106135-3), Ministry for Agriculture, Forestry and Fisheries, Republic of Korea.
} 


\section{Introduction}

Suppression of ammonia volatilization has been considered one of the most important issues, mainly facilitated by increasing nitrogen efficiency of urea in agriculture. Surfaceapplication of urea, a common method in agricultural field, has exposed the risk of high loss of nitrogen into air and water environments from soils because of its fast decomposition into ammonia on the soil surface. Actually, its loss could reach to more than $50 \%$ at a specific region through a volatilization of ammonia (Gioacchini et al., 2002). Recently, we developed a new type of $\mathrm{N}$ fertilizer (hereafter referred to as $\mathrm{MUCH}$ ) intercalating massive urea in interlayer space of montmorillonite (MMT). It showed a high $\mathrm{N}$ efficiency through smart suppression of ammonia volatilization without any changes in its inheritable character, fast effectiveness (Kim et al., 2011a; Kim et al., 2011b). Furthermore, we confirmed that physicochemical properties of soils were not significantly affected by $\mathrm{MUCH}$ treatment in sandy loam and clay loam soils on column experiment (Kim et al., 2011c).

Ammonia volatilization rate of urea depends on several factors such as the rate of its hydrolysis, weather conditions after application, and soil characteristics such as $\mathrm{pH}$, cation exchange capacity (CEC), and moisture content etc. (He et al., 2002; Nyord et al., 2008). Especially, high soil $\mathrm{pH}$ caused ammonia volatilization. Even at $\mathrm{pH}$ of 7.5 , ammonia volatilization increased twice that at $\mathrm{pH}$ of 6.0 (Overdahl et al., 1991.). Fan and Mackenzie (1993) showed the effect of acidic materials on ammonia loss to retard urea hydrolysis by reducing $\mathrm{pH}$ in the fertilizer micro-site. Therefore MUCH incorporated with acidic materials may have the effect to decrease $\mathrm{pH}$ of the micro-site applied with $\mathrm{MUCH}$.

Citric acid, in this study, was chosen as an acid because it is well known to increase available nutrient contents such as phosphorous and micronutrients through the metal-citrate complex (Drouillon and Merckx, 2003; Jones and Darrah, 1994). Furthermore, it also has the potential of $\mathrm{Al}$ detoxification in acidic soils. Therefore, the objective of this study was to synthesize MUCH incorporated with citric acid (hereafter referred to as Cit-MUCH) and to evaluate suppression effect of CitMUCH on $\mathrm{NH}_{3}$ volatilization.

\section{Materials and Methods}

Preparation and characterization of $\mathrm{MUCH}$ and CitMUCH Preparation of Cit-MUCH was attempted by the method slightly modified from the previous one (Kim et al., 2011a; Kim et al., 2011b), shown in Fig. 1. Addition amount of citric acid was chosen to be 2.0 weight $\%$ of metal-urea mixture. Metal salts used in this study were anhydrous forms of $\mathrm{CaCl}_{2}$ and $\mathrm{MgCl}_{2}$. Lumps of assynthesized $\mathrm{MUCH}$ and $\mathrm{Cit}-\mathrm{MUCH}$ were mildly grinded and stored in a tightly capped bottle for further experiment. All chemicals used in this experiment were of analytical grade. X-ray diffraction (XRD) patterns were obtained from an X-ray diffractometer (Rigaku JP/D/MAX-2200H, Tokyo) using Ni-filtered $\mathrm{Cu} \mathrm{Ka}$ radiation $(\lambda=1.5406 \AA)$ at $40 \mathrm{kV}$ and $30 \mathrm{~mA}$ at a scanning speed of $5^{\circ} \min ^{-1}$. A Fourier transform infrared (IR) spectrophotometer (Spectrum GX \& AutoImage, PerkinElmer, Waltham, MA) was used to obtain IR-spectra by standard $\mathrm{KBr}$ method in a frequency range of 4000 to $400 \mathrm{~cm}^{-1}$.

Pot experiment For evaluation $\mathrm{NH}_{3}$ volatilization from soils, the pot experiment was conducted with and without perilla plant [Perilla frutescens (L.) Britt.]. An air-dried soil used in pot experiments was chosen to have low $\mathrm{N}$ contents $\left(\sim 1 \mathrm{mg} \mathrm{kg}^{-1}\right)$. The physicochemical properties of soil are shown in Table 1.

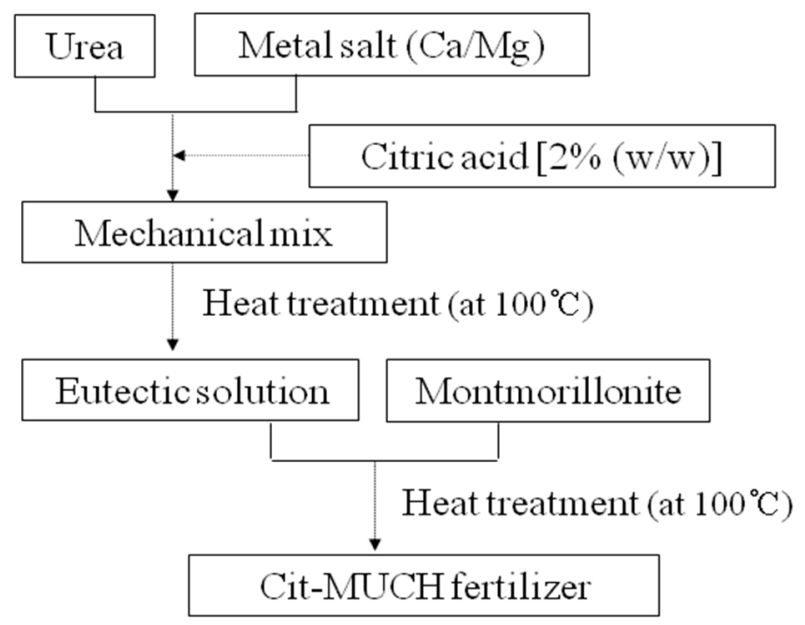

Fig. 1. Flow chart for preparation of MUCH incorporated citric acid.

Table. 1. Physicochemical properties of soil used in this study

\begin{tabular}{|c|c|c|c|c|c|c|c|c|c|}
\hline $\mathrm{pH}$ & $\mathrm{OM}$ & $\mathrm{Av} \cdot \mathrm{P}_{2} \mathrm{O}_{5}$ & $\mathrm{NH}_{4}-\mathrm{N}$ & $\mathrm{NO}_{3}-\mathrm{N}$ & $\mathrm{K}$ & $\mathrm{Ca}$ & $\mathrm{Mg}$ & $\mathrm{EC}$ & \multirow{2}{*}{ Texture } \\
\hline $1: 5$ & $\mathrm{~g} \mathrm{~kg}^{-1}$ & \multicolumn{3}{|c|}{------------ mg kg-1 ------------ } & ----- & cmolc $\mathrm{kg}^{-}$ & ------ & ds $\mathrm{m}^{-1}$ & \\
\hline 5.0 & 3.2 & 10 & 0.2 & 0.8 & 0.10 & 1.23 & 1.39 & 0.27 & Sand loam \\
\hline
\end{tabular}


The air-dried soil $(120 \mathrm{~g})$ was added to the pot $(\varnothing 7 \times 7$ $\mathrm{cm}$ ) and pre-incubated for 4 days to restore soil microbial activity. Soil water content was maintained to be equal to $50 \%$ of its field water holding capacity at room temperature. After incubation, either MUCH or Cit-MUCH was broadcasted onto soil surface at a rate of $500 \mathrm{mg}$ urea per pot. Six pots per each treatment were used for ammonia collection on a bare soil. For pot experiment with plant, a perilla seedling with two pairs of true leaves was transplanted into each pot and cultivated without any nutrient supplies. Water content of soil was kept to be 12 13 wt.\% by frequent supply of distilled water. After 20 days, either MUCH or Cit-MUCH was broadcasted on the surface of soil at a rate of $708 \mathrm{mg}$ urea per kilogram of soil.

Volatilized ammonia from the soil with and without perilla plant was collected by a closed-dynamic air flow method with slight modifications (Siva et al., 1999). The system consisted of an exchangeable chamber $(30 \times 30 \times 20$ $\mathrm{cm})$ and a trap (250-mL Erlenmeyer flask) fitted with an inlet/outlet. The emitted ammonia was collected in a trap (250-mL Erlenmeyer flask) containing $20 \mathrm{~mL}$ of $2 \mathrm{wt} . \%$ boric acid. An air flow was set at a rate of $2.4 \mathrm{~L} \mathrm{~min}^{-1}$ during collection. The collection was carried out for $1 \mathrm{~h}$ between 10:00 (a.m) and 12:00 (a.m) every day. $\mathrm{NH}_{3}$ concentration was determined by titration with a standard solution of $0.005 \mathrm{M} \mathrm{H}_{2} \mathrm{SO}_{4}$. All experiments were at least triplicated and data were analyzed by calculating mean standard errors and one-way analysis of variance. Significant differences were stated where $\mathrm{P}<0.05$. In this study, the effect of Cit-MUCH was merely compared to that of $\mathrm{MUCH}$ because the effect of MUCH on decrease of $\mathrm{NH}_{3}$ volatilization was well proved by previous study (Kim et al., 2011b; Kim et al., 2011c).

\section{Results and Discussion}

Fomation of eutectic solution Establishment of eutectic state depends generally on the type of reactants, their molar ratio, treatment temperature and duration. And formation of eutectic solution from reactants including solid form was visually examined by transparency. Eutectic solution of citric acid-incorporated $\mathrm{Ca} / \mathrm{Mg}$ complex developed transparent light blue (Fig. 2), indicating that citric acid was homogeneously distributed in Cit-Ca $\mathrm{a}_{0.7} / \mathrm{Mg}_{0.3}$ complex.

Characterization of Cit-MUCH To decrease $\mathrm{pH}$ of the site where urea is released, MUCH incorporated with citric acid was synthesized. The XRD pattern of Cit-MUCH was very similar to that of MUCH except there was a slight increase of $\mathrm{d}_{001}$ value in the basal spacing and appearance of peak at $24.12^{\circ} 2 \theta$ by incorporation of citric acid (Fig. 3). The basal spacing peaks of MUCH and

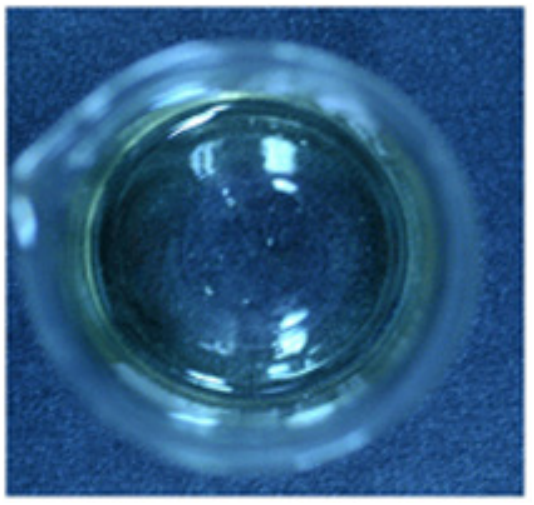

Fig. 2. Photograph of metal-urea eutectic solution incorporated with citric acid.

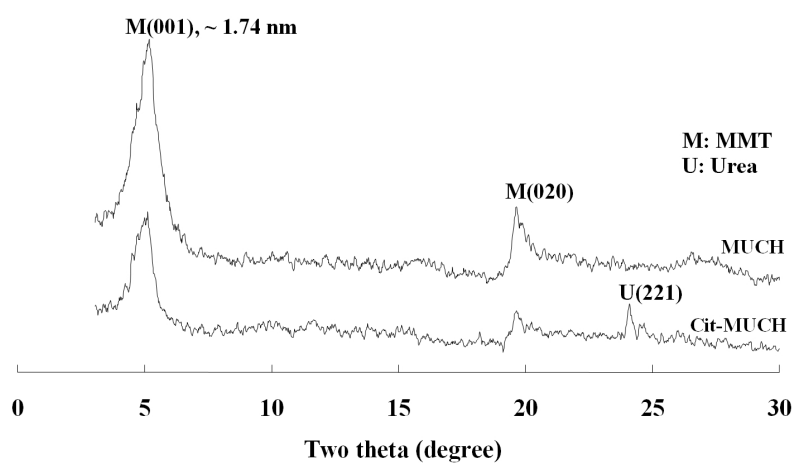

Fig. 3. XRD pattems Ca/Mg-MUCH and Cit-MUCH.

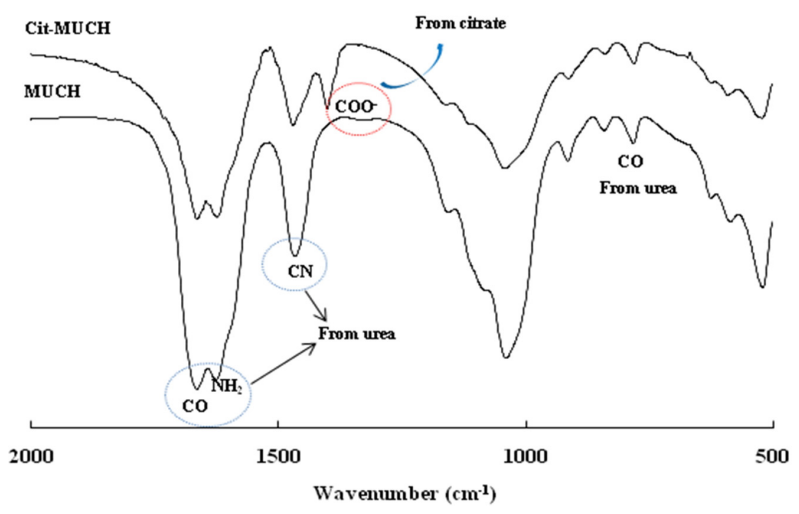

Fig. 4. IR spectra of $\mathrm{Ca} / \mathrm{Mg}-\mathrm{MUMH}$ and Cit-MUMH.

Cit-MUCH were about $1.74 \mathrm{~nm}$, meaning that massive intercalation of urea into MMT was successful in both synthesized materials because intercalation of the guest into MMT leads to expansion of the interlayer space by its longitudinal dimension (Brigatti et al., 2006; Kim et al., 2011b). It was supposed that a slight increase in the basal spacing and new peak at $24.12^{\circ} 2 \theta$ result from a change in urea arrangement of the complex. Meanwhile, both Cit-MUCH and MUCH have a typical peak at about $20^{\circ} 2 \theta$ originated from MMT structure. Incorporation of citric acid into MUCH was confirmed by the existence of $\mathrm{COO}^{-}$symmetric stretching vibration at $1401 \mathrm{~cm}^{-1}$ as shown 
Fig. 4 (Marchewaka and Pieraszko, 2003). Its IR spectrum also exhibited the red shift of $>\mathrm{C}=\mathrm{O}$ and $\mathrm{NH}_{2}$ vibration energy and the blue shift of $-\mathrm{C}-\mathrm{N}$ vibration energy as MUCH did (Kim et al., 2011a; Kim et al., 2011b). These IR bands are originated from urea molecules such as $\mathrm{CO}$, $\mathrm{NH}_{2}$ and $\mathrm{CN}$ vibration energy at 1685, 1632 and 1468 $\mathrm{cm}^{-1}$, respectively indicating that urea-metal complexes are well coordinated with between the $\mathrm{O}$ atom of a urea and metal cations such as $\mathrm{Ca}^{2+}$ and $\mathrm{Mg}^{2+}$ (Kim et al., 2011b). These results support that $\mathrm{Ca} / \mathrm{Mg}$-urea complex with and without citric acid are stabilized in interlayer of MMT.

Effect of citric acid-incomporated $\mathrm{MUCH} \mathrm{NH}_{3}$ volatilization High $\mathrm{NH}_{3}$ loss from soil surface applied with urea can be expected even in acidic soils due to high $\mathrm{NH}_{4}{ }^{+}$concentration and consequently alkaline $\mathrm{pH}$ in urea-applied micro-site (Fan and Mackenzie, 1993). Methods to reduce soil pH around the micro-site are the use of acidic materials such as humic acid and triple superphosphate (Ahmed et al.; 2008, Chien et al., 1987). Unfortunately, simple addition

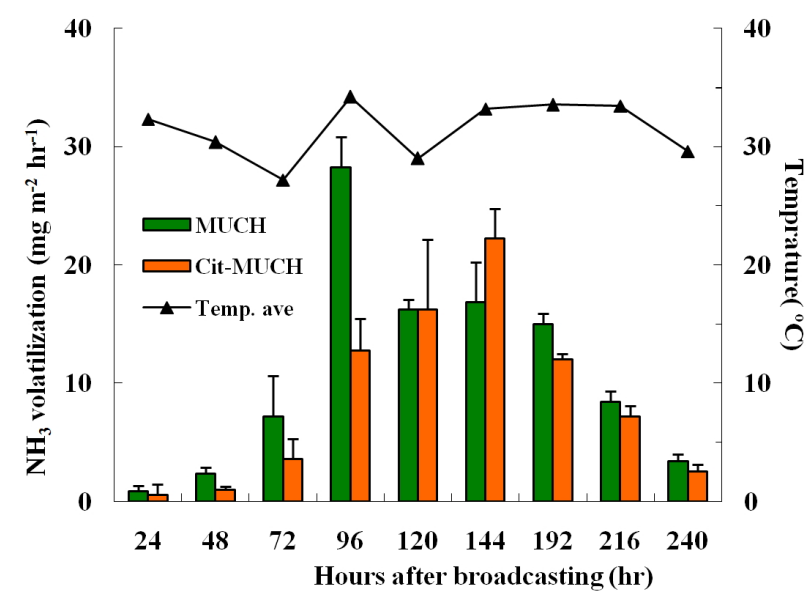

Fig. 5. Effect of the citric acid incorporated $\mathrm{MUCH}$ on $\mathrm{NH}_{3}$ volatilization from a bare soil.

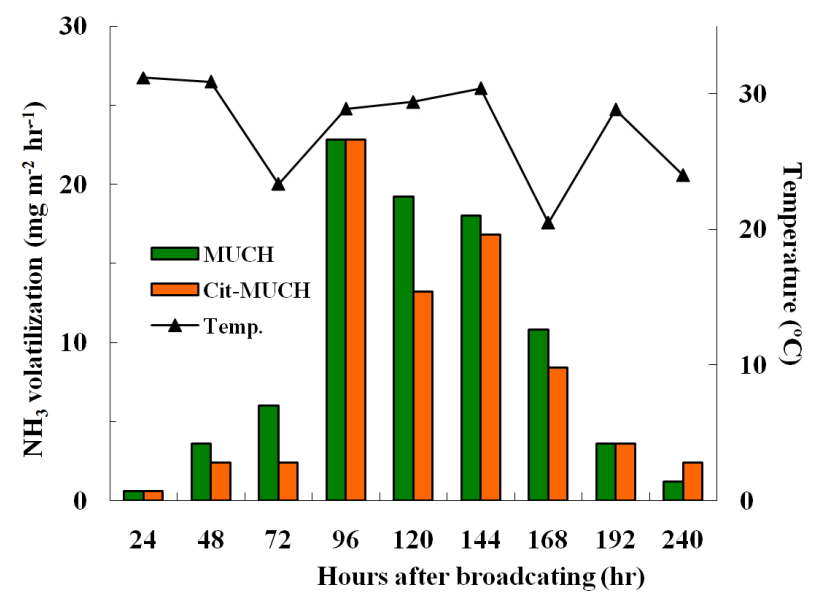

Fig. 6. Effect of the citric acid incorporated $\mathrm{MUCH}$ on $\mathrm{NH}_{3}$ volatilization from a perilla-planted soil. of these materials is not enough to reduce $\mathrm{NH}_{3}$ volatilization because of difficulty of their homogeneous distribution in soils. However, Cit-MUCH itself has a low $\mathrm{pH}$ of 6.4 due to coexistence of citric acid and urea in interlayer space of MMT into Cit-MUCH complex. The initial suppression of $\mathrm{NH}_{3}$ volatilization is clearly shown in Fig. 5. During the initial 4 days, $\mathrm{NH}_{3}$ volatilization from Cit-MUCH was remarkably reduced compared to that from $\mathrm{MUCH}$. A peak volatilization rate decreased from $28.3 \mathrm{~N} \mathrm{mg} \mathrm{m}^{-2} \mathrm{~h}^{-1}$ of MUCH-broadcast soil to $22.2 \mathrm{~N} \mathrm{mg} \mathrm{m}^{-2} \mathrm{~h}^{-1}$ of Cit-MUCHbroadcast soil, although more ammonia was volatilized from Cit-MUCH after 5 days. This result could be explained by the fact that citric acid retards $\mathrm{NH}_{3}$ volatilization until urea is degraded completely (Jones et al., 2003). Meanwhile, after 8 days, both soils showed a similar volatilization rate although slightly higher rate resulted from $\mathrm{MUCH}-$ broadcasted soil.

Behaviors of $\mathrm{NH}_{3}$ volatilization from Cit-MUCH in perillaplanted soils were very similar to those from unplanted soils (Fig. 6). Compared with unplanted soil, $\mathrm{NH}_{3}$ volatilization was less in planted soils until $72 \mathrm{hrs}$. This result could be explained by two reasons; The first is that the use of nitrogen sources by plant successively reduces a concentration of $\mathrm{NH}_{3}$ dissolved in soil water, and the second is due to the quick exhaustion of citrate in soils by plant root and microorganism (Jones and Darrah, 1994). Therefore, it is clear that the remarkable suppression of the initial ammonia volatilization could be achieved by the incorporation of citric acid.

\section{Conclusions}

MUCH incorporated with citric acid was successfully synthesized by simple addition of citric acid and its incorporation was confirmed through XRD pattern and IR absorbance. Cit-MUCH showed more smart suppression of $\mathrm{NH}_{3}$ volatilization during the initial 3 days than $\mathrm{MUCH}$ in both bare and prilla-planted soils. Furthermore, citric acid has the function to increase available nutrient contents such as phosphorous and micronutrients through the metalcitrate complex. Therefore, Cit-MUCH is expected to contribute to sustainable agriculture.

\section{References}

Ahmed, O.H., A. Husin, and A.H. Hanif. 2008. Ammonia volatilization and ammonium accumulation from urea mixed with zeolite and triple superphosphate. Acta Agr Scand B-S P 58:182-184.

Brigatti, M.F., E. Galan, and B.K.G. Theng. 2006. Structures and mineralogy of clay minerals: Hand book of clay science; Edited by F. Bergaya, B.K.G. Theng, and G. 
Lagaly, Development $\mathrm{s}$ in clay science 1, Elsevier, Amsterdam, pp 19-86.

Chien, S.H., C.B. Christianson, M.S. Lupin, and G.E. Peters. 1987. Compaction of metal sal-urea complexes with triple superphosphate. Fert Res 14:181-191.

Drouillon M. and R. Merckx. 2003. The role of citric acid as a phosphorus mobilization mechanism in high P-fixing soils. Gayana Bot. 60:55-62.

Fan, M.X. and A.F. Mackenzie. 1993. Urea and phosphate interactions in fertilizer microsites: ammonia volatilization and $\mathrm{pH}$ changes. Soil Sci. Soc. Am. J. 57:839-845.

Gioacchini, P., A. Nastri, C. Marzadori, C. Giovannini, L.V. Antisari, and C. Gessa. 2002. Influence of urease and nitrifi cation inhibitors on $\mathrm{N}$ losses from soils fertilized with urea. Biol. Fertil. Soils 36:129-135.

He, Z.L., D.V. Calvert, A.K. Alva, Y.C. Li, and D.J. Banks. 2002. Clinoptilolite zeolite and cellulose amendments to reduce ammonia volatilization in a calcareous sandy soil. Plant Soil 247:253-260.

Jones, D.L., 1999. Amino acid biodegradation and its potential effects on organic nitrogen capture by plants. Soil Biol. Biochem. 31:613-622.

Jones, D.L. and P.R. Darrah. 1994. Role of root derived organic acids in the mobilization of nutrients from the rhizosphere. Plant Soil 166:247-257.

Jones, D.L., P.G. Dennisand, A.G. Owen, and P.P.W. Van Hees. 2003. Organic acid behavior in soil-misconceptions and knowledge gaps. Plant Soil 248:31-41.

Kim, K.S., M. Park, C.L. Choi, D.H. Lee, Y.J. Seo, C.Y. Kim, J.S. Kim, S.-I. Yun, H.-M. Ro, and S. Komarneni. 2011a. Suppression of $\mathrm{NH}_{3}$ and $\mathrm{N}_{2} \mathrm{O}$ emissions by massive urea intercalation in montmorillonite. J. Soils Sediments 11:416-422.

Kim, K.S., M. Park, W.T. Lim, and S. Komarneni. 2011 b. Massive intercalation of urea in montmorillonite. Soil Sci. Soc. Am. J. 75:2361-2366.

Kim, K.S., C.L. Choi, D.H. Lee, Y.J. Seo, and M. Park. 2011c. Release pattern of urea from metal-urea-clay hybrid with montmorillonite and its impact on soil property. Korean J. Soil Sci. Fert. 44:545-550.

Marchewaka, M.K. and A. Pieraszko. 2003. Structure and spectra of melaminium citrate. J Phys Chem Solids 64:2169-2181

Nyrod, T., K.M. Schelde, H.T. Søgaard, L.S. Jensen, and S.G. Sommer. 2008. A simple model for assessing ammonia emission from ammoniacal fertilizers as affected by $\mathrm{pH}$ and injection into soil. Atmos Environ 42:4656-4664.

Overdahl, C.J., G.W. Rehm, and H.L. Meredith, 1991. Fertilizer urea. Extension service (WW-00636-GO) of University of Minnesota. http://www.extension.umn.edu/distribution/cropsystems

Siva K.B., H. Aminuddin, M.H.A. Husni, and A.R. Manas. 1999. Ammonia volatilization from urea as affected by tropical-based palm oil palm effluent (pome) and peat. Commun Soil Sci Plant Anal 30:785-804. 